\title{
Effect of Fiber Percentage and Stacking Sequence on Mechanical Performance of Unidirectional Hemp and Palmyra Reinforced Hybrid Composites
}

\author{
Varanasi Lakshmi Narayana ${ }^{1 *}$, Lokavarapu Bhaskara Rao ${ }^{1}$, Siva Bhaskara Rao Devireddy ${ }^{2}$ \\ ${ }^{1}$ School of Mechanical \& Building Sciences, VIT University, Chennai, Tamil Nadu 600, India \\ ${ }^{2}$ Department of Mechanical Engineering, St. Ann's College of Engineering and Technology, Andhra Pradesh 523187, India
}

Corresponding Author Email: vlakshmi.narayana2014@vit.ac.in

https://doi.org/10.18280/rcma.303-405

Received: 3 May 2020

Accepted: 2 June 2020

\section{Keywords:}

hybrid composites, mechanical properties, natural fibers, scanning electron microscope, water absorption

\begin{abstract}
The use of natural fiber reinforced composites gains attention due to its weight and reasonable strength in the recent years. Generally, the mechanical performance of the hybrid composites are superior than the mono fiber reinforced composites. In this work, two different types of natural fibers, namely hemp and palmyra fibers, are selected as reinforcement materials for the development of unidirectional fiber reinforced hybrid composites. Composite laminate was fabricated with four different weight percentages (10 wt.\%, 20 wt.\%, 30 wt.\% and $40 \mathrm{wt} . \%)$ and three different hybrid ratios (1:1, 1:2, and 2:1) of hemp and palmyra. The influence of fiber percentage and stacking sequence on the mechanical performance such as tensile strength, flexural strength, impact energy, and hardness of the hybrid composites was evaluated. From the results, it was observed that the adding $30 \mathrm{wt} . \%$ of hemp and palmyra fiber can increase the tensile strength and flexural strength by a percentage of $112 \%$ and $241 \%$ respectively. The impact energy absorption and the hardness of the hybrid composites are examined and compared. The experimental results shows that the hybrid composites containing high fiber weight percentage contribute to significant increase in impact energy and hardness. Morphological analysis is done using Scanning Electron Microscope (SEM).
\end{abstract}

\section{INTRODUCTION}

Natural fibers are ecofriendly, low cost, low density, and sustainable natural resources that have been a significant demand in recent years. Current production trends shows that these materials are established as reinforcement material in the use of structural, automobile parts, nonstructural and composite panels. The natural fibers such as jute, vakka, hemp, sisal, date, coir, bamboo, banana, elephant grass, areca, flax, abaca, pineapple, kenaf, and husk fiber are the extensively used fibers for fabricating the polymer composites. Recently, many research works are going on in this field [1-4]. For instance, Shibata et al. [5] investigated the effect of fiber loading on flexural properties of the unidirectional bamboo and kenaf fiber reinforced composites and the results revealed that the optimum flexural modulus is obtain at 60 vol. $\%$ for kenaf fiber and 72 vol.\% for bamboo fiber. Similarly, Maleque et al. [6] have studied the flexural and impact properties of woven banana fiber reinforced epoxy composites and their results indicated that the impact strength and flexural strength by 40 and $38 \%$ respectively. Neves et al. [7] studied the comparative mechanical properties of hemp fiber reinforced composites by using the matrix epoxy and polyester. From the study it was reported that the epoxy composites gives maximum tensile and flexural properties as compared to polyester composites.

Recently, researchers investigated that hybridization with two or more natural fibers in the matrix material to prepare hybrid composites which will improve the properties that cannot be found in single type of reinforcement [8]. Bledzki et al. [9] studied the mechanical characteristics of unidirectional hemp and flax fiber reinforced epoxy composites. From the results it is concluded that by addition of reinforcement the modulus and strength of the hybrid composites are improved. In another study, the effect of fiber loading and hybridization on mechanical properties of short randomly oriented sisal and banana fibers reinforced polyester composites were evaluated by Idicula, et al. [10]. The results revealed that the hybrid composite with $40 \%$ volume fraction and relative volume ratio of banana and sisal 3:1 shows the maximum tensile strength, flexural strength and impact energy as compared to other weight ratios 1:1 and 1:3. Devireddy and Biswas [11] investigated the mechanical properties of unidirectional banana and jute fiber reinforced epoxy composites. It is observed that the mechanical properties of hybrid composite materials give best results when compared with the individual banana and jute fiber composites. Tensile and impact properties of sisal and coconut sheath fiber reinforced polyester hybrid composites has been evaluated by kumar et al. [12].The experimental results indicated that the stacking sequence plays an important role and the composite stack with coconut sheath/sisal/coconut sheath is given the better properties.

Velmurugan and Manikandan [13] studied the mechanical performance of palmyra and glass fiber reinforced hybrid composites and it is found that the palmyra fiber as core and glass fiber as skin exhibits improved mechanical properties. Despite the numerous advantages offered by natural fibres, 
these materials are susceptibility to water absorption. Water absorption percentage of the newly developed composite is one important characteristic that needs to be observed because this controls the end use applications. Jawaid et al. [14] evaluated the water absorption and density of the oil palm empty fruit bunches (EFB)/jute fiber reinforced epoxy composites. The composite prepared with EFB/jute/EFB stacking sequence gives better resistance to water absorption as compared to composite with stacking sequence jute/EFB/jute. Sathish et al. [15] investigated the effect of stacking sequence and fiber orientation on the thermal and mechanical properties of banana and kenaf reinforced epoxy composites and the result indicated that the composite fabricated with $45^{\circ}$ fiber orientation has improved properties than the others. The influence of stacking sequence on the impact damage mechanisms of flax and basalt reinforced epoxy composites was evaluated by Ricciardi et al. [16]. From the results it is evidenced that the damage propagation and characteristics are affected by the hybridization and stacking sequence. Bharath et al. [17] investigated the impact of stacking sequence on mechanical properties of coconut leaf sheath/jute/E-glass reinforced composites. The revealed that the stacking sequence plays an important role to improve the tensile strength, flexural strength, impact energy and hardness of the hybrid composites.

Hemp (Cannabis sativa L.) fiber is one of the oldest natural fiber second largest grown bast fiber in world after jute. Hemp fiber does not need any additional investment in terms of fertilizer, herbicides or pesticides to grow well [18]. The high stiffness and strength of hemp fibers makes them a as reinforcement material in composite fabrication. Palmyra palm (Borassus flabellifer) is another most important natural fiber and widely used in the region of South-East Asia and Africa because of its advantages like high modulus of rigidity, high tensile strength, and flexural strength are imparted along the longitudinal direction. The above review shows that there is a lot research works had been done on the hybrid composites, but the studies on the of effect of stacking sequence and development of hybrid composites reinforced with hemp fiber and palmyra fiber as a constitutes in lesser dimension. In this connection, the present study establishes the physical and mechanical properties of hemp and palmyra reinforced hybrid composites for better utilization of agricultural waste materials for making value added products.

\section{EXPERIMENTAL}

\subsection{Materials}

Hemp and palmyra fibers are used for composite fabrication, testing, and to study the physical and mechanical characteristics. The unidirectional hemp fiber was procured from the local market and the palmyra fiber is extracted from outer bask of the palm tree from a local sources. The physical, mechanical and chemical properties of hemp and palmyra fibers are presented in Table 1. The cellulous, pectin, lignin and microfibril angle plays a significant role in the mechanical properties of the composites. The unidirectional continuous hemp and palmyra fibers were chopped into $30 \mathrm{~cm}$ length and prepared in a layers form as shown in Figure 1. The epoxy matrix (LY 556) and with the hardener (HY 951) were supplied by Sree industrial composite products, Hyderabad.
Table 1. Properties of hemp and palmyra fiber

\begin{tabular}{ccc}
\hline Property & Hemp fiber & Palmyra fiber \\
\hline Density $\left(\mathrm{g} / \mathrm{cm}^{3}\right)$ & 1.47 & 1.03 \\
Tensile strength $(\mathrm{MPa})$ & $200-240$ & $290-350$ \\
Tensile modulus $(\mathrm{GPa})$ & $3.5-4.0$ & $5-5.4$ \\
\% elongation & $2-4$ & $2-4.5$ \\
Cellulous content $(\%)$ & 74.4 & 49.6 \\
Hemicelluloses $(\%)$ & 17.9 & 18 \\
Lignin content $(\%)$ & 3.7 & 21.2 \\
Moisture content $(\%)$ & 12 & 12.08 \\
\hline
\end{tabular}

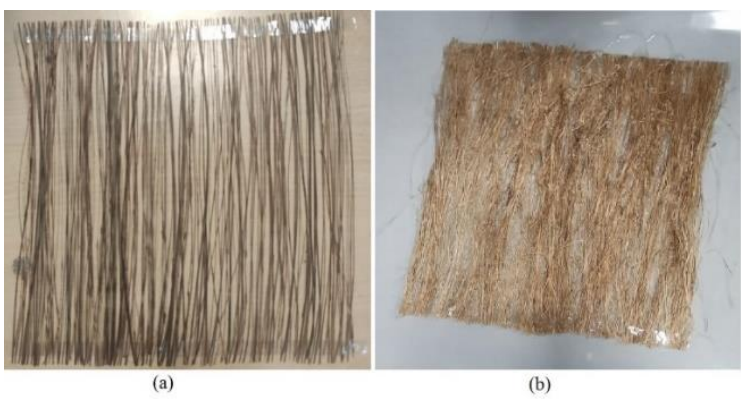

Figure 1. Individual layers of (a) Plamyra fiber and (b) Hemp fiber

\subsection{Composite preparation}

The unidirectional hybrid composite laminates were fabricated by hand layup process. The fibers are orientated uniformly in the longitudinal direction attachment to attain the unidirectional material property. The layers were arranged by varying stacking sequences as well as keeping the relative hybrid ratios of the hemp and palmyra as $1: 1,2: 1$, and $1: 2$. The unidirectional hemp and palmyra fibers were arranged three different stacking sequences as shown in Figure 2.

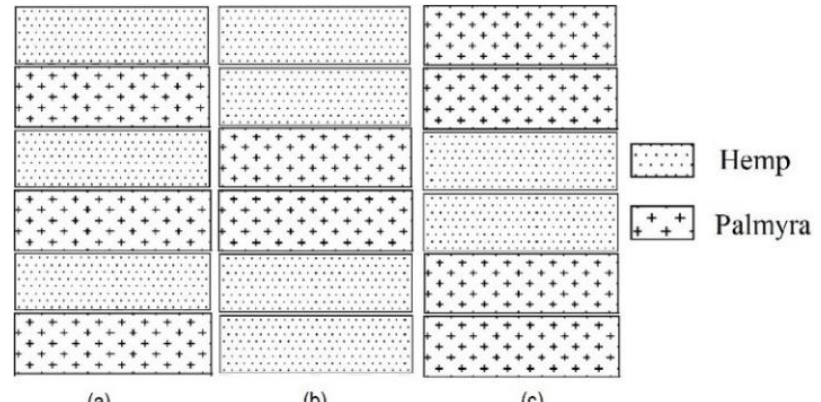

(a)

(b)

(c)

Figure 2. Arrangement of fibers in stacking sequence (a) HPHPHP (b) HHPPHH (c) PPHHPP

Twelve different types of hybrid composites were prepared with various weight percentage of reinforcement $10 \mathrm{wt} . \%, 20$ wt. $\% 30$ wt. $\%$ and 40 wt. $\%$ as shown in Table 2 . A mold release sheet and mold release spray was used for easy removal of the hybrid composite. The blending ratio of the epoxy resin and the corresponding hardener is 10:1 by weight is applied between layers of fibers for an effective binding. During the composite fabrication the air gaps and voids are removed carefully by means of a roller. After rolling, the mold is closed and loaded under the compressive pressure for proper curing at atmospheric temperature for $48 \mathrm{hrs}$. After the curing process, the composite samples were cut to the cut into necessary dimensions given in the ASTM standards to measure physical and mechanical properties. 
Table 2. Detailed designation and composition of fabricated composites

\begin{tabular}{|c|c|c|c|c|c|}
\hline Composite & Stack sequence & Hemp (wt.\%) & Palmyra (wt.\%) & Overall (wt.\%) & Matrix (wt.\%) \\
\hline $\mathrm{C} 1$ & HPHPHP & 5 & 5 & 10 & 90 \\
\hline $\mathrm{C} 2$ & НРНРНР & 10 & 10 & 20 & 80 \\
\hline $\mathrm{C} 3$ & НРНРНР & 15 & 15 & 30 & 70 \\
\hline $\mathrm{C} 4$ & НРНРНP & 20 & 20 & 40 & 60 \\
\hline C5 & ННРPНН & 6.7 & 3.3 & 10 & 90 \\
\hline C6 & ННРРНН & 13.4 & 6.6 & 20 & 80 \\
\hline C7 & ННРРНН & 20 & 10 & 30 & 70 \\
\hline $\mathrm{C} 8$ & ННРРНН & 26.7 & 13.3 & 40 & 60 \\
\hline $\mathrm{C} 9$ & РРННРP & 3.3 & 6.7 & 10 & 90 \\
\hline $\mathrm{C} 10$ & РPННРP & 6.6 & 13.4 & 20 & 80 \\
\hline $\mathrm{C} 11$ & РPННРP & 10 & 20 & 30 & 70 \\
\hline $\mathrm{C} 12$ & PРНHРP & 13.3 & 26.7 & 40 & 60 \\
\hline
\end{tabular}

\subsection{Physical and mechanical testing of hybrid composites}

\subsubsection{Density and void percentage}

The actual density $\left(\rho_{\mathrm{ca}}\right)$ of the hybrid composites were found from the Archimedes principle according to ASTM D 792-91 standard. The theoretical density of the hybrid composites is found from the weight fractions and densities of individual constituents by using the following Eq. (1).

$$
\rho_{\mathrm{ct}}=\frac{1}{\left(\mathrm{~W}_{\mathrm{fh}} / \rho_{\mathrm{fh}}\right)+\left(\mathrm{W}_{\mathrm{fp}} / \rho_{\mathrm{fp}}\right)+\left(\mathrm{W}_{\mathrm{m}} / \rho_{\mathrm{m}}\right)}
$$

where, $\rho$ and $\mathrm{W}$ represent the density and weight fraction, respectively. The suffixes $\mathrm{fh}, \mathrm{fp}$, and $\mathrm{m}$ stand for the hemp fiber, palmyra fiber, and matrix respectively. The void percentage $(\mathrm{Vv})$ of the hybrid composite is calculated from the actual density and theoretical density according to ASTM D 2734-70 standard using the following Eq. (2).

$$
\mathrm{V}_{\mathrm{v}}=\frac{\rho_{\mathrm{ct}}-\rho_{\mathrm{ca}}}{\rho_{\mathrm{ct}}}
$$

\subsubsection{Water absorption}

Water absorption tests are performed according to ASTM D570-98 with the specimen dimension of $60 \mathrm{~mm} \times 10 \mathrm{~mm} \times$ $4 \mathrm{~mm}$. In order to measure the water absorption percentage, the composite specimens were immersed in distilled water at room temperature. The samples were taken out from the water for every $24 \mathrm{hr}$ and wiped with tissue paper to measure the weight gain. The samples weight gain is noted regularly from 24-288 hrs. The water absorption percentage is measured from the weight difference by using Eq. (3).

$$
\mathrm{M}_{\mathrm{t}}(\%)=\frac{\left(\mathrm{W}_{\mathrm{f}}-\mathrm{W}_{\mathrm{i}}\right)}{\mathrm{W}_{\mathrm{i}}} \times 100
$$

where, $\mathrm{M}_{\mathrm{t}}$ is water absorption, $\mathrm{W}_{\mathrm{f}}$ is the final weight of the sample at different time intervals and $\mathrm{W}_{\mathrm{i}}$ is the initial weight.

\subsubsection{Tensile test}

The tensile tests are conducted by applying uniaxial load on both the ends of composite specimens using tensometer. The test is conducted as per ASTM D3039-76 test standards. The test specimen is having dimensions $153 \mathrm{~mm} \times 12.7 \mathrm{~mm} \times 4$ $\mathrm{mm}$. The samples were tested at a loading rate of $5 \mathrm{~mm} / \mathrm{min}$. The tensile force was noted with respect to the gauge length. For each composite designation, three identical samples were tested and mean value is obtained.

\subsubsection{Flexural test}

Three point bending test is performed to find the flexural strength of the hybrid composites. The specimens were cut into as per ASTM D790 standard with the dimension of 100 $\mathrm{mm} \times 12.4 \mathrm{~mm} \times 4 \mathrm{~mm}$. The test is performed on the same tensometer at $5 \mathrm{~mm} / \mathrm{min}$ rate of loading with a gauge length of $40 \mathrm{~mm}$. From the test the breaking load was noted to estimate the flexural strength by using Eq. (4). For each composite designation, three identical samples were tested and mean value is obtained.

$$
\frac{3 \mathrm{PL}}{2 b t^{2}}
$$

where, $\mathrm{P}$ is maximum load $(\mathrm{N}), \mathrm{L}$ is the gauge length of the sample $(\mathrm{mm}), \mathrm{b}$ is the width of specimen $(\mathrm{mm})$ and $\mathrm{t}$ is the thickness of specimen $(\mathrm{mm})$.

\subsubsection{Interlaminar shear strength test}

To observe the interlaminar shear strength (ILSS) of the hybrid composite specimens, short beam shear tests were done according to ASTM standard D2344. The test was performed on universal testing machine Instron 1195. The dimension of specimen $45 \mathrm{~mm} \times 10 \mathrm{~mm} \times 4 \mathrm{~mm}$ is used with the testing speed of $2 \mathrm{~mm} / \mathrm{min}$. In each composite designation, three samples were tested, and the mean value is observed. The ILSS of the hybrid composite samples are calculated using the Eq. (5).

$$
\frac{3 \mathrm{P}}{4 \mathrm{bt}}
$$

\subsubsection{Impact test}

The impact energy of the composite specimens were measured by using low velocity Izod impact tester provided by VEEKAY test lab, India. The test was performed as per ASTM standard D 256 with the dimension of the sample is $64 \mathrm{~mm} \times$ $12.7 \mathrm{~mm} \times 4 \mathrm{~mm}$. The amount of energy required to break the composite specimen can be easily measured by using impact test. For each composite, three identical samples were tested and average value is obtained.

\subsubsection{Micro hardness}

The Vickers hardness of the composite specimens was measured using a Leitz micro hardness tester according to ASTM D785 test standard. The test was performed by applying load $24.54 \mathrm{~N}$ with the diamond indenter into the 
surface of the specimen to generate an indentation. Vickers hardness number is calculated using the Eq. (6).

$$
H_{v}=0.1889 \frac{F}{L^{2}}
$$

where, $\mathrm{Hv}$ is the Vickers hardness number, $\mathrm{F}$ is the applied load in $\mathrm{N}$ and $\mathrm{L}$ is the diagonal of square impression in $\mathrm{mm}$. For each type of composite, three samples are tested and the average value was recorded.

2.3.8 Interfacial analysis using Scanning Electron Microscope The micro structure and failure modes of the tensile tested hybrid composites are observed by scanning electron microscope JEOL JSM-6480LV. The broken portions of the specimens were cut and mounted on stubs with silver paste for inspection.

\section{RESULTS AND DISCUSSION}

\subsection{Density and void percentage}

Density of the polymer composites is one of the important parameter because of their low densities these materials are replaced by conventional materials. The density values of hemp fiber, palmyra fiber and pure epoxy are found to be 1.47 $\mathrm{g} / \mathrm{cm}^{3}, 1.03 \mathrm{~g} / \mathrm{cm}^{3}$, and $1.15 \mathrm{~g} / \mathrm{cm}^{3}$ respectively. The effect of fiber percentage and stacking sequence on theoretical and experimental densities along with the void percentage of the hemp and palmyra fiber reinforced composites are presented in Table 3 .

Table 3. Theoretical, experimental densities and void percentage of the composites

\begin{tabular}{cccc}
\hline Composite & $\begin{array}{c}\text { Theoretical } \\
\text { density } \\
\left(\mathbf{g} / \mathbf{c m}^{\mathbf{3}}\right)\end{array}$ & $\begin{array}{c}\text { Experimental } \\
\text { density } \\
\left(\mathbf{g} / \mathbf{c m}^{\mathbf{3}}\right)\end{array}$ & $\begin{array}{c}\text { Void } \\
\text { percentage } \\
(\boldsymbol{\%})\end{array}$ \\
\hline C1 & 1.156 & 1.144 & 1.039 \\
C2 & 1.162 & 1.141 & 1.808 \\
C3 & 1.168 & 1.138 & 2.569 \\
C4 & 1.174 & 1.134 & 3.407 \\
C5 & 1.149 & 1.137 & 1.044 \\
C6 & 1.148 & 1.125 & 2.003 \\
C7 & 1.148 & 1.113 & 3.049 \\
C8 & 1.147 & 1.101 & 4.011 \\
C9 & 1.163 & 1.152 & 0.945 \\
C10 & 1.176 & 1.157 & 1.615 \\
C11 & 1.188 & 1.161 & 2.272 \\
C12 & 1.202 & 1.167 & 2.912 \\
\hline
\end{tabular}

The void percentage of the hybrid composites increases as the fiber percentage increases due of the hydrophilic nature of the hemp and palmyra fibers. At $40 \mathrm{wt} \%$ of fiber percentage, the void percentage increases to $3.407 \%, 4.011 \%$ and $2.912 \%$ for hybrid composites with stacking sequence of hemp and palmyra as HPHPHP, HHPPHH, and PPHHPP, respectively. It can also be seen from the table that the theoretically calculated density results are higher as compared to the actual density results. The reason behind this is, while evaluating the theoretical density it has been assumed that the composites are free from defects and voids, while in experimental fabrication of composites inescapably gives increase the certain amount of voids within the hybrid composite material. From the results, it is also found that the void percentage is minimum for hybrid composites with stacking sequence of hemp and palmyra fiber as PPHHPP. The reason may be due to the good reinforcement and matrix interfacial bonding, the reduced lumen size of palmyra fiber, and perfect wetting of palmyra fiber by epoxy matrix. Similar type of observations found by previous researchers [19].

\subsection{Water absorption}

Figure 3 illustrates the effect of stacking sequence and fiber percentage on the water absorption performance of the hemp and palmyra fiber reinforced epoxy composites. The amount of water absorption percentage increases as the fiber percentage increases and the maximum percentage of water absorption is found at $40 \mathrm{wt} . \%$ of fiber percentage. This is due to addition of hemp and palmyra fibers into the matrix leads to increase the polar hydroxide groups, which penetrate the more amount of water through the cellulose structure of the hemp fiber and palmyra fiber. The maximum water absorption percentage of the hybrid composites is observed $12.16 \%$, $12.63 \%$, and $11.55 \%$ with stacking sequence of HPHPHP, НHРPHН, and РPHНPP, respectively. Further, it is observed that the water absorption percentage is tremendous increases when hemp fiber was positioned as skin layer and palmyra fiber was positioned as core layer. It is also found that the rate of water absorption is linear at the starting with immersion time and stabilize over a certain period of time. Several researchers [20] are investigated that the water absorption percentage increases with increase in fiber content.

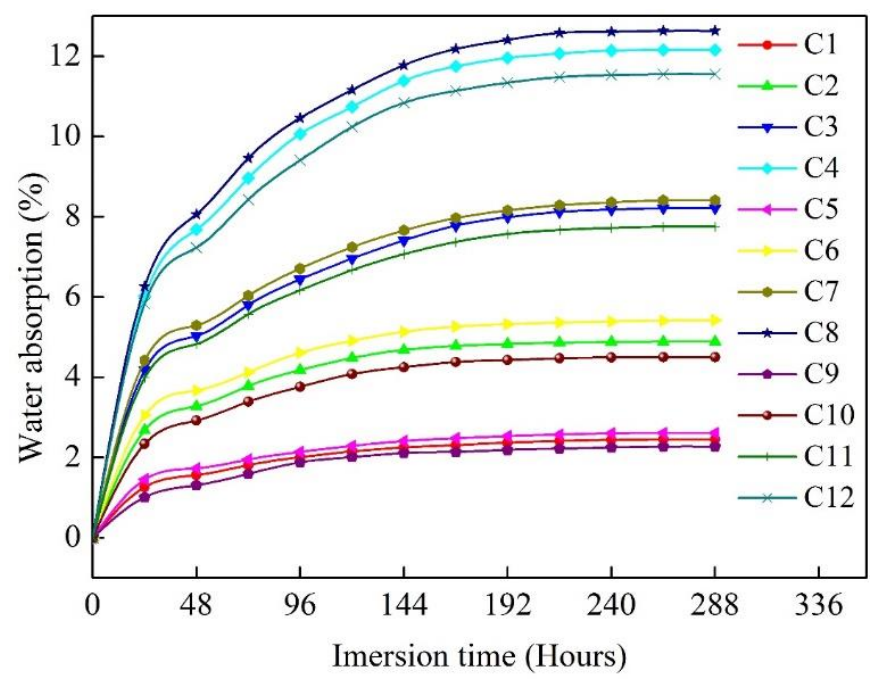

Figure 3. Water absorption performance of hemp and palmyra fiber reinforced epoxy composites

\subsection{Tensile strength}

The effect of fiber percentage and hybrid ratio on the tensile strength of hemp and palmyra fiber reinforced epoxy composites is shown in Figure 4. There is a considerable difference in tensile strength due to change in fiber percentage and layering pattern two fibers. The tensile strength of the pure epoxy is found $32.28 \mathrm{Mpa}$. The tensile strength of the hybrid composites increases up to $30 \mathrm{wt}$. \% of fiber percentage and then start decreases at $40 \mathrm{wt}$. \% fiber percentage. At $30 \mathrm{wt} . \%$ of fiber percentage, the tensile strength increases to $66.82 \mathrm{MPa}$, $59.32 \mathrm{MPa}$, and $71.75 \mathrm{MPa}$ with stacking sequence of 
HPHPHР, HНPPHН, and PРHHPP, respectively. When the weight percentage of fiber increases to $30 \mathrm{wt} . \%$, the tensile strength of hybrid composites increases to $107 \%, 83 \%$, and $122 \%$ in the hybrid composites with stacking sequence of HPHPHP, HНPPHH, and PPHHPP, respectively. As the fiber weight percentage is increased, the hemp and palmyra fibers makes epoxy matrix ductile and elongation at break is increased. The stress transferred from reinforcement to the matrix can be propagated without failure of the hybrid composite [21]. This increases the tensile strength of the hybrid composite at higher weight percentage of fiber. Table 4 shows the comparison of tensile strength of hybrid composites with individual hemp and palmyra fiber reinforced composites.

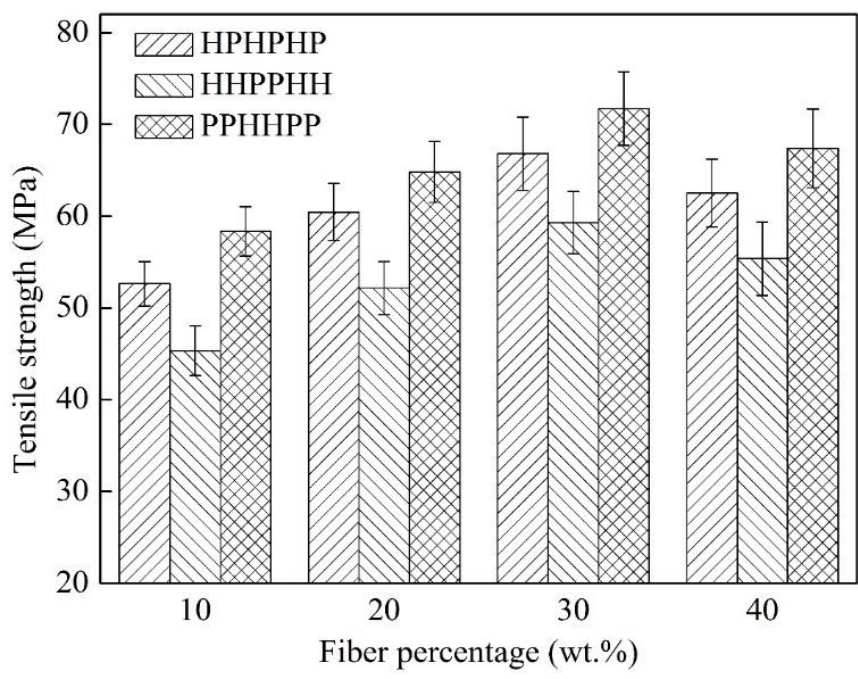

Figure 4. Tensile strength of hemp and palmyra fiber reinforced epoxy composites

Table 4. Comparison of tensile strength (MPa) of hybrid, hemp and palmyra fiber reinforced composites

\begin{tabular}{cccc}
\hline $\begin{array}{c}\text { Fiber } \\
\text { percentage }\end{array}$ & Hybrid & Hemp [7] & Palmyra [13] \\
\hline 0 & 32.28 & 38.81 & 33 \\
10 & 58.37 & 40.66 & 26.20 \\
20 & 64.84 & 40.83 & 35.04 \\
30 & 71.75 & 50.46 & 39.83 \\
\hline
\end{tabular}

\subsection{Flexural strength}

The study of unidirectional fiber reinforced composites subjected to flexural test is very complex. In flexural test, the hybrid composite specimens are subjected to normal stresses and shear stresses. Figure 5 depict the flexural strength of hemp and palmyra fiber reinforced hybrid composites as a function of fiber percentage and different stacking sequences. The flexural strength of the pure epoxy is found 32.28 Mpa. By incorporating the hemp and palmyra fiber in to the epoxy the flexural strength of hybrid composites is increases up to 30 wt. $\%$ and then decreases with further increase in fiber percentage up to $40 \mathrm{wt} . \%$. The increase in flexural strength while increased fiber percentage due to the good bonding between the reinforcement and matrix and resistance to shearing. At $30 \mathrm{wt} \% \%$ of fiber percentage, the flexural strength increases to $101.83 \mathrm{MPa}, 92.71 \mathrm{MPa}$, and $110.31 \mathrm{MPa}$ with stacking sequence of HPHPHP, HHPPHH, and PPHHPP, respectively. The percentage improvement from neat epoxy to
30 wt. \% of fiber percentage in НРНРНР, ННРРНH, and PPHHPP layering hybrid composites are found $215 \%, 187 \%$ and $241 \%$, respectively. From the Figure, flexural strength was found to be maximum when palmyra fiber was used as the skin material and hemp fiber as the core material. The intrinsic properties of palmyra fiber is higher than hemp fiber, which means that the main load bearing capacity is observed by palmyra fiber as the skin material as compared to the hemp fiber as the skin material. Table 5 shows the comparison of flexural strength of hybrid composites with individual hemp and palmyra fiber reinforced composites.

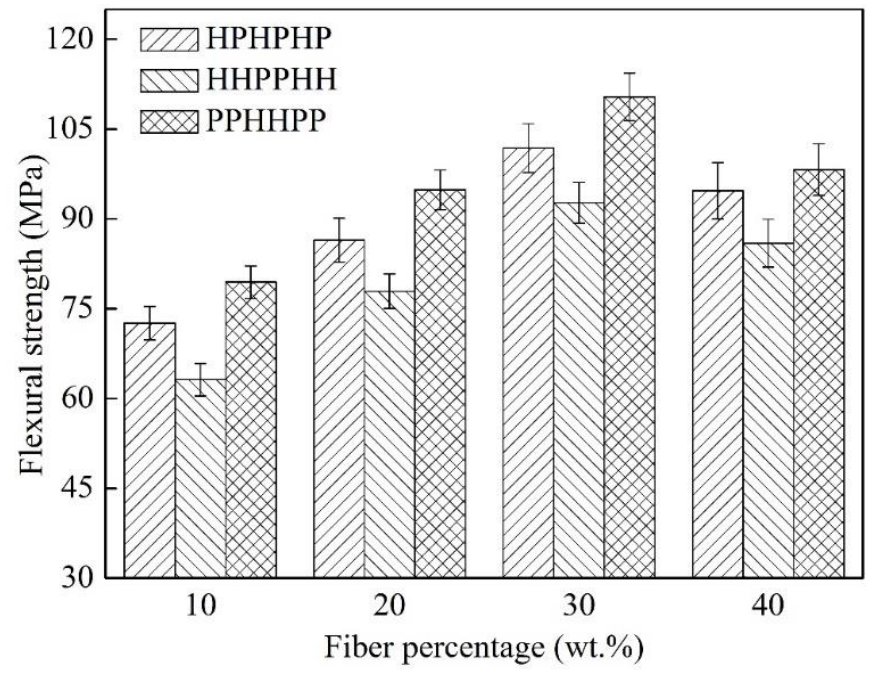

Figure 5. Flexural strength of hemp and palmyra fiber reinforced epoxy composites

Table 5. Comparison of flexural strength (MPa) of hybrid, hemp and palmyra fiber reinforced composites

\begin{tabular}{cccc}
\hline $\begin{array}{c}\text { Fiber } \\
\text { percentage }\end{array}$ & Hybrid & Hemp [7] & Palmyra [13] \\
\hline 0 & 32.28 & 38.81 & 40.60 \\
10 & 58.37 & 40.66 & 44.45 \\
20 & 64.84 & 40.83 & 49.15 \\
30 & 71.75 & 50.46 & 56.25 \\
\hline
\end{tabular}

\subsection{ILSS}

The effects of fiber percentage and stacking sequence on ILSS values of the hemp and palmyra fiber reinforced hybrid composites are illustrated in Figure 6. The ILSS of the neat matrix is observed to be $6.92 \mathrm{MPa}$. As can be seen, ILSS values of the hybrid composites are increased considerably when the fiber percentage is increased from $10 \mathrm{wt} . \%$ to 30 wt. $\%$ and then start decreased at $40 \mathrm{wt} . \%$. The ILSS is mainly depends on fiber-matrix interfacial bonding and matrix properties. The decrease of ILSS at maximum fiber percentage is due to the voids present in the matrix. With addition of 30 wt.\% of fiber percentage, the ILSS of neat epoxy show an improvement by $123 \% 93 \%$ and $149 \%$ with respect to with stacking sequence of HPHPHP, HHPPHH, and PPHHPP, respectively. At $30 \mathrm{wt} \% \%$ of fiber percentage, the maximum ILSS values were found to be $15.47 \mathrm{MPa}, 13.41 \mathrm{MPa}$, and 17.27 $\mathrm{MPa}$ for the hybrid composites with stacking sequence of HPHPHP, HHPPHH, and PPHHPP, respectively. It could be seen that the stacking sequence PPHHPP possessed the maximum shear strength, compared with those of HPHPHP and HHPPHH stacking sequences. 


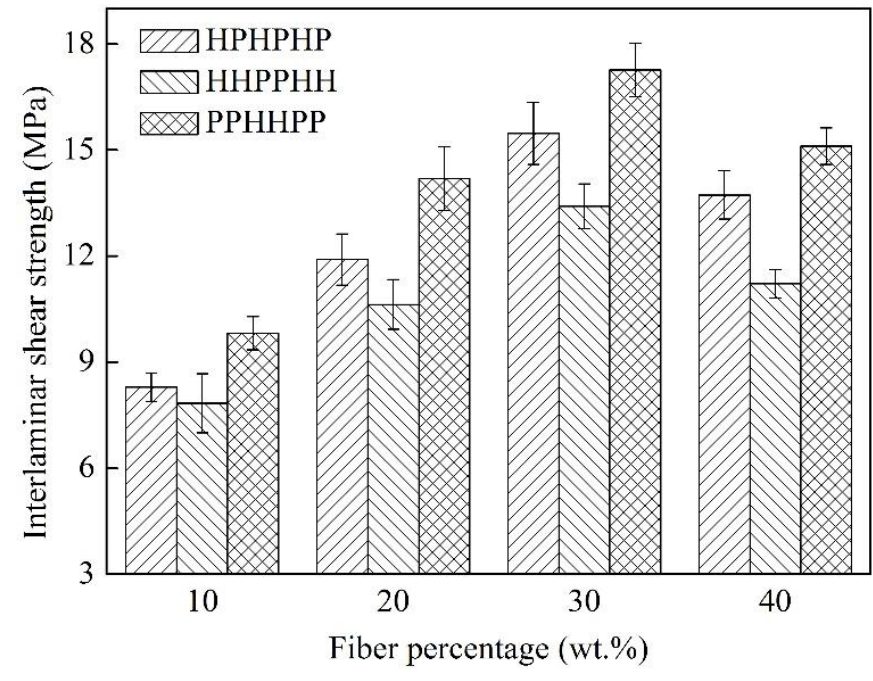

Figure 6. Interlaminar shear strength of hemp and palmyra fiber reinforced epoxy composites

\subsection{Impact energy}

The impact energy of composites depended on several factors such as the reinforcement/matrix interface, the nature of the individual constituents, the geometry and construction of the composite, and composite testing conditions. The influences of fiber percentage and hybrid ratio on impact energy of the hemp and palmyra fiber reinforced hybrid composites are shown in Figure 7.

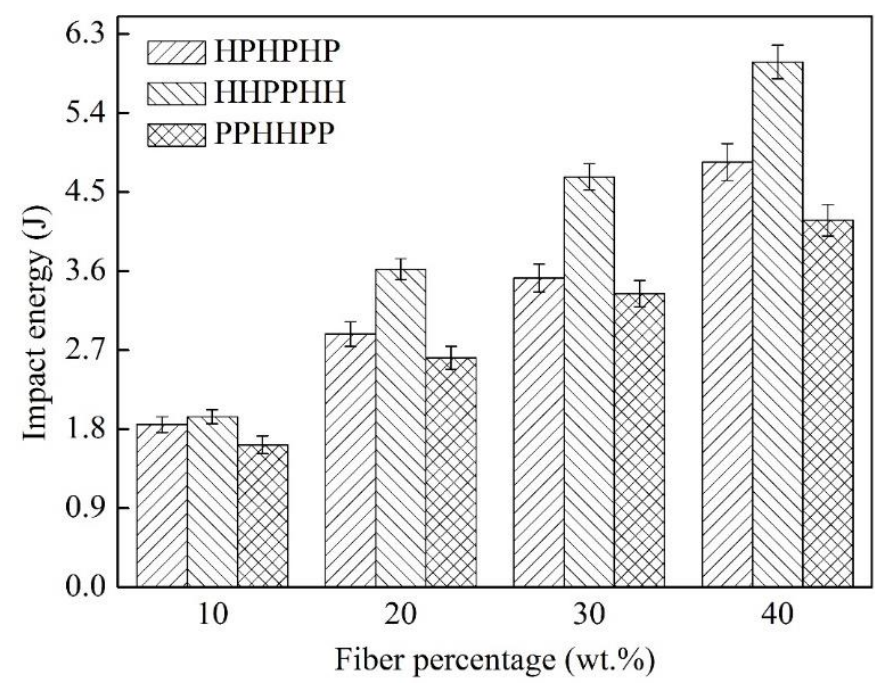

Figure 7. Impact energy of hemp and palmyra fiber reinforced epoxy composites

The impact resistance is observed to increase linearly with increase in fiber percentage up to $40 \mathrm{wt}$. \%. The impact energy of neat epoxy is only $1.05 \mathrm{~J}$. The impact energy of the hybrid composite with stacking sequence of HPHPHP, HНPPHН and PPHHPP laminate is found $4.84 \mathrm{~J}, 5.98 \mathrm{~J}$ and $4.18 \mathrm{~J}$, respectively. Compare to the pure epoxy, the impact energy performance is improved by $360 \%, 469 \%$ and $298 \%$ for the hemp and palmyra composite with stacking sequence of HPHPHP, HНPPHH and PPHHPP, respectively. It is found from the figure that hybrid composites with the stacking sequence of hemp and palmyra fiber as HHPPHH reveals the higher impact energy capacity as compared to other two stacking sequences of HPHPHP and PPHHPP. The high impact energy is found in hemp fiber as a skin layer is due to the high spiral angle and higher lumen size [22].

\subsection{Micro hardness}

Figure 8 presents the hardness values of the various hybrid composites investigated under this study. It is found from this figure that the hardness of the hemp and palmyra reinforced epoxy composites increase gradually with the fiber percentage increasing from $10 \mathrm{wt}$. $\%$ to $40 \mathrm{wt}$. $\%$ for all the stacking sequences. At $40 \mathrm{wt} . \%$ fiber percentage, the hybrid composite with stacking sequence PPHHPP showing the hardness value 44.8 which is more than other stacking sequences HPHPHP and HHPPHH that have hardness values of 42.6 and 39.6 respectively. The reason for increase in hardness due to the better distribution of palmyra fibers into the epoxy with minimum void percentage and good interfacial bonding between the epoxy and reinforcement. Several researchers [23] reported the similar trend of results and indicated that stacking sequence plays an important role in determining the hardness of the composite.

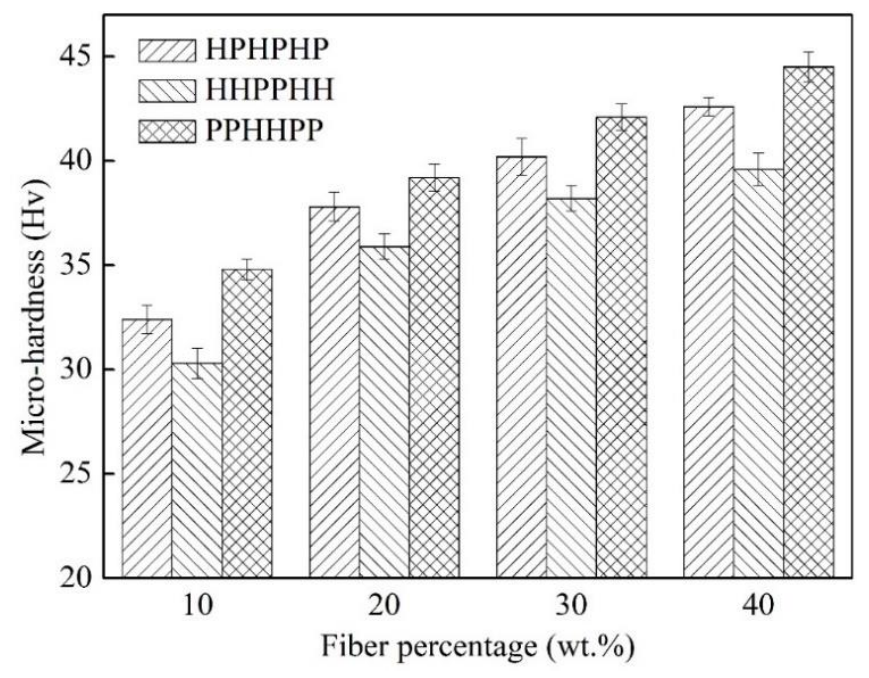

Figure 8. Micro hardness of hemp and palmyra fiber reinforced epoxy composites

\subsection{Interfacial analysis using Scanning Electron Microscope}

In order to study the interfacial bonding at the interfaces, the scanning electron microscope images are taken for the tensile tested specimen at maximum values. Figure 9 shows the scanning electron microscope image for the neat epoxy and hybrid composites at 30wt. \% of fiber percentage which subjected to tensile test. The image illustrates the fiber breakage of the hemp and palmyra fibers, reinforcementmatrix interaction and fiber pullout characteristics reinforcement. Figure 9(b), (c), and (d) illustrated the hybrid composites with stacking sequence of hemp and palmyra fiber as PPHHPP, HPHPHP, and HHPPHH, respectively. From the figure 9 (b) it is found that the distributions of hemp and palmyra fibers in the matrix material are more uniform with the stacking sequence PPHHPP as compare to other stacking sequence HPHPHP and HHPPHH. It is observed that the good interfacial bonding between the reinforcement and the matrix at $30 \mathrm{wt}$. \% of fiber percentage that leads to improve the strength properties of hybrid composites. 


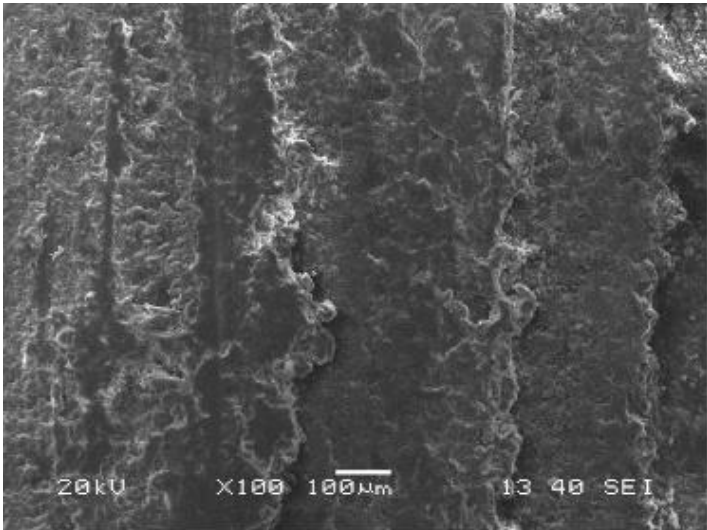

(a)

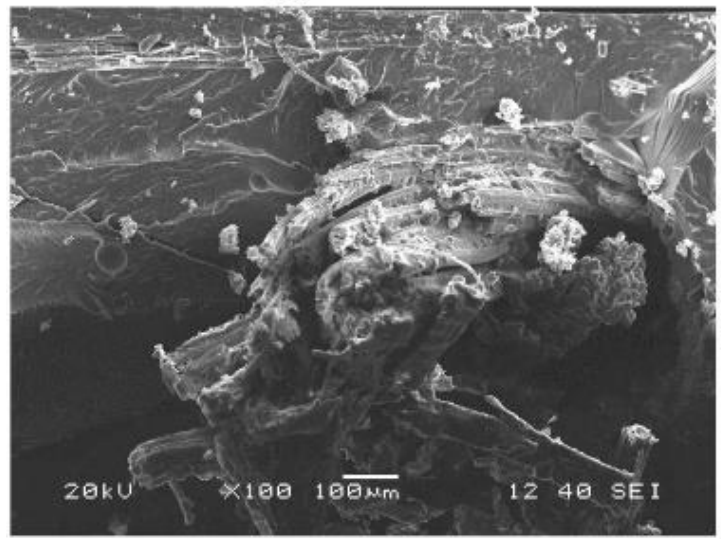

(c)

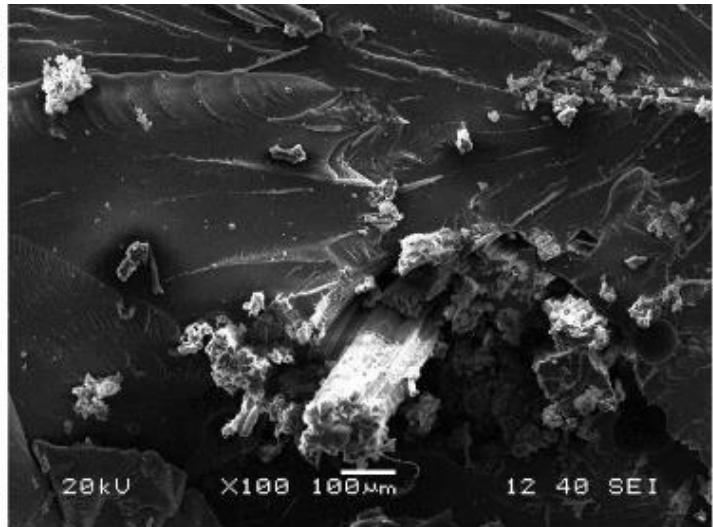

(b)

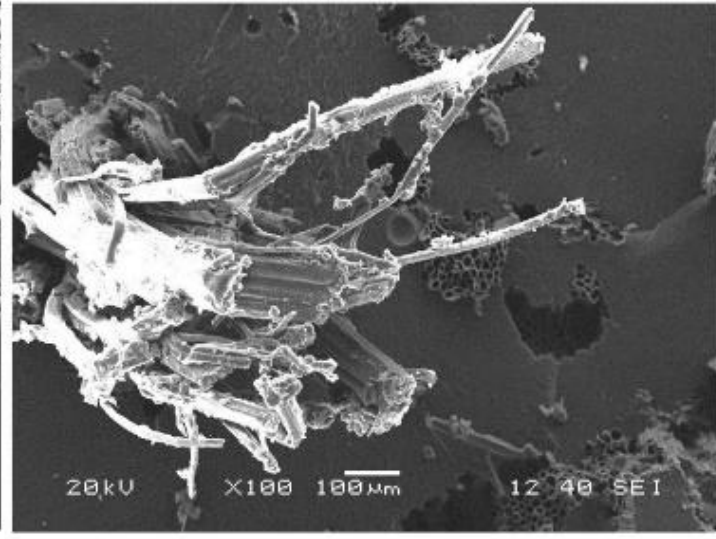

(d)

Figure 9. Scanning Electron Microscope images of tensile tested neat epoxy and hybrid composites with 30 wt. \% of fiber percentage

\section{CONCLUSIONS}

The effect of stacking sequence and fiber percentage on physical and mechanical properties hemp and palmyra reinforced hybrid composites was studied. Based on the experimental investigation, the following conclusions are derived:

- By incorporation of hemp and palmyra fibers in to the epoxy matrix, the void percentage and water absorption percentage of hybrid composites increases.

- The results showed that the composites with $30 \mathrm{wt} . \%$ of fiber percentage and PPHHPP stacking sequence shows maximum tensile strength and flexural strength of $71.75 \mathrm{MPa}$ and $110.31 \mathrm{MPa}$ respectively.

- The impact energy and hardness of the composites increase with fiber percentage up to $40 \mathrm{wt}$. \%. The ultimate impact energy of $2.98 \mathrm{~J}$ is observed for the stacking sequence HHPPHH and the Better hardness of 44.8 is obtained for the stacking sequence PPHHPP.

- The mechanical properties of the hybrid composite specimen with stacking sequence PPHHPP and $30 \mathrm{wt} \%$ of fiber percentage is the optimum combination for better values as compared to HPHPHP and HHPPHH stacking sequences of the composite laminate.

\section{REFERENCES}

[1] Sapuan, S.M., Leenie, A., Harimi, M., Beng, Y.K. (2006). Mechanical properties of woven banana fibre reinforced epoxy composites. Materials \& Design, 27(8): 689-693. https://doi.org/10.1016/j.matdes.2004.12.016

[2] Devi, L.U., Bhagawan, S.S., Thomas, S. (1997). Mechanical properties of pineapple leaf fiber-reinforced polyester composites. Journal of Applied Polymer Science, 64(9): 1739-1748. http://dx.doi.org/10.1002/(SICI)10974628(19970531)64:9\%3C1739::AIDAPP10\%3E3.0.CO;2-T

[3] Hepworth, D.G., Hobson, R.N., Bruce, D.M., Farrent, J.W. (2000). The use of unretted hemp fibre in composite manufacture. Composites part A: Applied Science and Manufacturing, 31(11): 1279-1283. https://doi.org/10.1016/S1359-835X(00)00098-1

[4] Subrahmanyam, B.V., Krishna, S.G., Kumar, R.J., Devireddy, S.B.R. (2019). Experimental and micromechanical thermal characteristics of jute fiber reinforced polyester composites. Materials Today: Proceedings, 18: 350-356. https://doi.org/10.1016/j.matpr.2019.06.311

[5] Shibata, S., Cao, Y., Fukumoto, I. (2008). Flexural modulus of the unidirectional and random composites made from biodegradable resin and bamboo and kenaf fibres. Composites part A: Applied Science and Manufacturing, 39(4): 640-646. https://doi.org/10.1016/j.compositesa.2007.10.021

[6] Maleque, M.A., Belal, F.Y., Sapuan, S.M. (2007). Mechanical properties study of pseudo-stem banana fiber reinforced epoxy composite. The Arabian Journal for Science and Engineering, 32(2B): 359-364. 
[7] Neves, A.C.C., Rohen, L.A., Mantovani, D.P., Carvalho, J.P., Vieira, C.M.F., Lopes, F.P., Simonassi, N.T., da Luz, F.S., Monteiro, S.N. (2020). Comparative mechanical properties between biocomposites of Epoxy and polyester matrices reinforced by hemp fiber. Journal of Materials Research and Technology, 9(2): 1296-1304. https://doi.org/10.1016/j.jmrt.2019.11.056

[8] Hariharan, A.B.A., Khalil, H.A. (2005). Lignocellulosebased hybrid bilayer laminate composite: Part I-Studies on tensile and impact behavior of oil palm fiber-glass fiber-reinforced epoxy resin. Journal of Composite Materials, $39(8)$ : 663-684. https://doi.org/10.1177/0021998305047267

[9] Bledzki, A.K., Fink, H.P., Specht, K. (2004). Unidirectional hemp and flax EP-and PP-composites: Influence of defined fiber treatments. Journal of Applied Polymer Science, 93(5): 2150-2156. https://doi.org/10.1002/app.20712

[10] Idicula, M., Joseph, K., Thomas, S. (2010). Mechanical performance of short banana/sisal hybrid fiber reinforced polyester composites. Journal of Reinforced Plastics and Composites, 29(1): 12-29. https://doi.org/10.1177/0731684408095033

[11] Devireddy, S.B.R., Biswas, S. (2017). Physical and mechanical behavior of unidirectional banana/jute fiber reinforced epoxy based hybrid composites. Polymer Composites, 38(7): 1396-1403. https://doi.org/10.1002/pc.23706

[12] Kumar, K.S., Siva, I., Rajini, N., Jeyaraj, P., Jappes, J.W. (2014). Tensile, impact, and vibration properties of coconut sheath/sisal hybrid composites: Effect of stacking sequence. Journal of Reinforced Plastics and Composites, 33(19): 1802-1812. https://doi.org/10.1177/0731684414546782

[13] Velmurugan, R., Manikandan, V. (2007). Mechanical properties of palmyra/glass fiber hybrid composites. Composites Part A: Applied Science and Manufacturing, 38(10): 2216-2226 https://doi.org/10.1016/j.compositesa.2007.06.006

[14] Jawaid, M.H.P.S., Khalil, H.A., Khanam, P.N., Bakar, A.A. (2011). Hybrid composites made from oil palm empty fruit bunches/jute fibres: Water absorption, thickness swelling and density behaviours. Journal of Polymers and the Environment, 19(1): 106-109. https://doi.org/10.1007/s10924-010-0203-2

[15] Sathish, P., Kesavan, R., Ramnath, B.V., Vishal, C. (2017). Effect of fiber orientation and stacking sequence on mechanical and thermal characteristics of bananakenaf hybrid epoxy composite. Silicon, 9(4): 577-585. https://doi.org/10.1007/s12633-015-9314-7

[16] Ricciardi, M.R., Papa, I., Lopresto, V., Langella, A., Antonucci, V. (2019). Effect of hybridization on the impact properties of flax/basalt epoxy composites: influence of the stacking sequence. Composite Structures, 214: $476-485$ https://doi.org/10.1016/j.compstruct.2019.01.087

[17] Bharath, K.N., Sanjay, M.R., Jawaid, M., Harisha, Basavarajappa, S., Siengchin, S. (2019). Effect of stacking sequence on properties of coconut leaf sheath/jute/E-glass reinforced phenol formaldehyde hybrid composites. Journal of Industrial Textiles, 49(1): 3-32. https://doi.org/10.1177/1528083718769926

[18] Dayo, A.Q., Gao, B.C., Wang, J., Liu, W.B., Derradji, M., Shah, A.H., Babar, A.A. (2017). Natural hemp fiber reinforced polybenzoxazine composites: curing behavior, mechanical and thermal properties. Composites Science and Technology, 144: 114-124. https://doi.org/10.1016/j.compscitech.2017.03.024

[19] Jawaid, M., Khalil, H.A., Hassan, A., Abdallah, E. (2012). Bi-layer hybrid biocomposites: chemical resistant and physical properties. BioResources, 7(2): 2344-2355. http://dx.doi.org/10.15376/biores.7.2.23442355

[20] Hassan, M.M., Wagner, M.H., Zaman, H.U., Khan, M.A. (2010). Physico-mechanical performance of hybrid betel nut (Areca catechu) short fiber/seaweed polypropylene composite. Journal of Natural Fibers, 7(3): 165-177. https://doi.org/10.1080/15440478.2010.504394

[21] Kumar, R.P., Amma, M.G., Thomas, S. (1995). Short sisal fiber reinforced styrene-butadiene rubber composites. Journal of Applied Polymer Science, 58(3): 597-612. https://doi.org/10.1002/app.1995.070580315

[22] Jawaid, M., Alothman, O.Y., Paridah, M.T., Khalil, H.S.A. (2014). Effect of oil palm and jute fiber treatment on mechanical performance of epoxy hybrid composites. International Journal of Polymer Analysis and Characterization, $\quad$ 19(1): 62-69. https://doi.org/10.1080/1023666X.2014.858429

[23] Venkata Reddy, G., Venkata Naidu, S., Shobha Rani, T. (2008). Kapok/glass polyester hybrid composites: tensile and hardness properties. Journal of Reinforced Plastics and Composites, 27(16-17): 1775-1787. https://doi.org/10.1177/0731684407087620 